\title{
The role of rice straw-based hydrogels on some soil microorganisms strains
}

\author{
O. El-Hady, ${ }^{1}$, S. A. Abo-Sedera, ${ }^{2} \underline{\text { A. H. Basta }}{ }^{3^{*}}$ and $\underline{\text { H.EL-Saied }}^{3 *}$ \\ ${ }^{1}$ Soil and Water Utilization Department, ${ }^{2}$ Agricultural Microbiology Department, ${ }^{3}$ Cellulose \& Paper \\ Department, National Research Centre, Dokk-12622i, Cairo, Egypt. \\ *Corresponding authors.E-mails address_Houssni_nrc@yahoo.com,_Altaf_Basta2004@yahoo.com, and \\ marelhady41@yahoo.com; Fax: 202-33370931,Tel: 33335926
}

doi:10.5618/bio.2011.v1.n1.6 || Received: 21-12-2011, Accepted: 15-1-2012, Available online: 17-1-2012

\begin{abstract}
Due to the shortage in natural conditioners for sandy and sandy calcareous soils, i.e., clays, manures and composts, considerable attention has been paid to use synthesized hydrophilic formulations (hydrogels). For economic and environmental purposes, the present work deals on using rice straw waste (RS) as a substrate for preparation of low cost hydrogels. Four formulations of RS-based hydrogels (G1-G4) were prepared, and applied to desert soil. Their effect on some of the beneficent micro-organisms in plant rhizosphere was evaluated. These microorganisms are: five sps. of Rizobia liguminsorum, Azotobacter chroococcum, Azospirillum Lipoferium), Bacillus supllis ,phosphate dissolving bacteria (Bacellus megatherium), Actinomycetes(Crepresented by streptomyces aureofaciens.) as well as fungi (Aspergillu niger). The results obtained indicate that, the investigated hydrogels have stimulating effect on the studied microorganisms. The hydrogels prepared from using $\mathrm{H}_{2} \mathrm{O}_{2}$ /ferrous ammonium sulfate as grafting initiation system and neutralizing the final hydrogels by nitric acid provide higher efficiency than hydrogels from grafting by persulfate/persulfite initiation system with the same neutralizing agent. Pre-cyanoethylating the RS promote the efficiency of hydrogel produced from persulfate/persulfite initiation grafting process and the acetic acid to neutralize the final product. This behavior was evaluated through determining the studied microorganisms counts besides dehydrogenase and phosphatase activities in the rhizosphere_of 60 days old wheat plants grown in a sandy calcareous soil conditioned with the recom-mended rates of such products, i.e., 0.25-0.5\% on dry soil weight basis. Due to the adverse effect of applying the higher rate of $G$, i.e., $0.5 \%$, on the aeration of the rootzone, incorporating the lower one $(0.25 \%)$ in the soil is preferred.
\end{abstract}

Keywords: Rice straw, Grafted rice straw, Hydrogels, Sandy soil, Microorganisms.

\section{Introduction}

For the urgent need to meet food and dress demands in most developing countries, e.g., Egypt, the cultivation of spread desert areas either sandy or calcareous has an attention of the Egyptian Government in last decades.. Such soils are poor with respect to their physic-bio-chemical properties, soilwater plant relationships as well as their nutritional status.

Incorporating gel forming polymers in sandy and sandy calcareous soils is one of the techniques in conditioning such soils. This class of polymers was first introduced for agricultural use in the early 1980's $[1,2]$.These polymers don't possess linear chain structures but the chains are rather cross-linked to form a three-dimensional net work [3,4]. Depending on synthesis conditions as well as type and density of covalent bonds that form crosslinking, these polymers are capable of absorbing hundreds of times their weight of water and can expand greatly when hydrated and are claimed to remain active for a much longer time $[5,6]$. On the other hand, hydrogels of high water absorbency and water keeping capacity from sugar cane bagasse, cotton stalks, and newsprint paper wastes, as local lignocelluloses wastes were prepared via graft polymerization reaction. $[7,8]$.

For utilizing rice straw as undesirable agro-waste, our previous work focused on preparation of RS-based hydrogels via initiating the grafting processes by using different initiating systems. It was found that grafting of pre-cyanoethylated RS and using persulfate-persulfite initiation system provide hydrogels with relatively higher absorption capacities for both distilled and Nile water [9].

Micro-organisms such as bacteria, fungi and actinomycetes are influenced profoundly the physical, chemical and especially the biological properties of soils. The impact effect of such organisms include the modification and decomposition of plant residues and 
other organic materials and the formation of humus, which regards the most chemically and physically active group of compounds in the soil. One result of these processes of decay is the release, from organic forms, of essential plant nutrients, such as nitrogen, phosphorus and sulfur. Subsequently still other microorganisms can oxidize, reduce and otherwise change the state of the nutrient elements in the soil. These changes have profound influence on plant growth and otherwise affect soil properties in addition to the role of organic fertilizers as amendments for improving physical and chemical characteristics of the soil, which in turn reflected on rhizosphere microflora, plant growth and yield $[10,11]$.

The present study aims at studying the direct effect of applying RS-based hydrogels, as conditioners for sandy and calcareous soils on some beneficent soil micro-organisms strains. In this respect four different hydrogels [9], with higher absorption behavior were chosen for this study. The study includes:

a. Effect of the prepared hydrogels as growth promoters for beneficent micro- organisms (stimulating activity).

b. Effect of the prepared hydrogels on biological activity of soils via determining: (i) total counts of bacteria, fungi and actinomycetes in the rizosphere of indicator plants, and (ii) dehydrogenase and phosphotase_activities.

\section{MATERIALS AND METHODS}

\subsection{Materials}

2.1.1 Soil. Surface sample of a sandy calcareous soil was collected from El-Saff area, Giza Govemorate, Egypt. The main analytical data of the soil, which were carried out according to Page et al. and Klute $[12,13]$, are presented in Table 1.

2.1.2. Examined hydrogels. Four hydrogels from the previous examined twelve prepared formulations [9], were chosen for the present study. These gels have relatively high absorption capacity for both distilled and Nile water $\left(250 \mu \mathrm{g} \cdot \mathrm{g}^{-1} \quad\right.$ salts $)$. The water absorption capacities of the chosen hydrogels , i.e., Salt /Dry x 1000 (w/w) were 7610, 3318, 3008 and 7061 in distilled water; while 6107, 2025, 3128 and $3789 \%$ in Nile water for $G_{1}, G_{2}, G_{3}$ and $G_{4}$, respectively. While, for nitrogen content were 8.04, $8.04,7.11$ and $8.91 \%$, respectively. The conditions of preparing these hydrogels were reported elsewhere [9], which summarized as follow;

Table 1: Analytical data of El-Saff sandy calcareous soil.

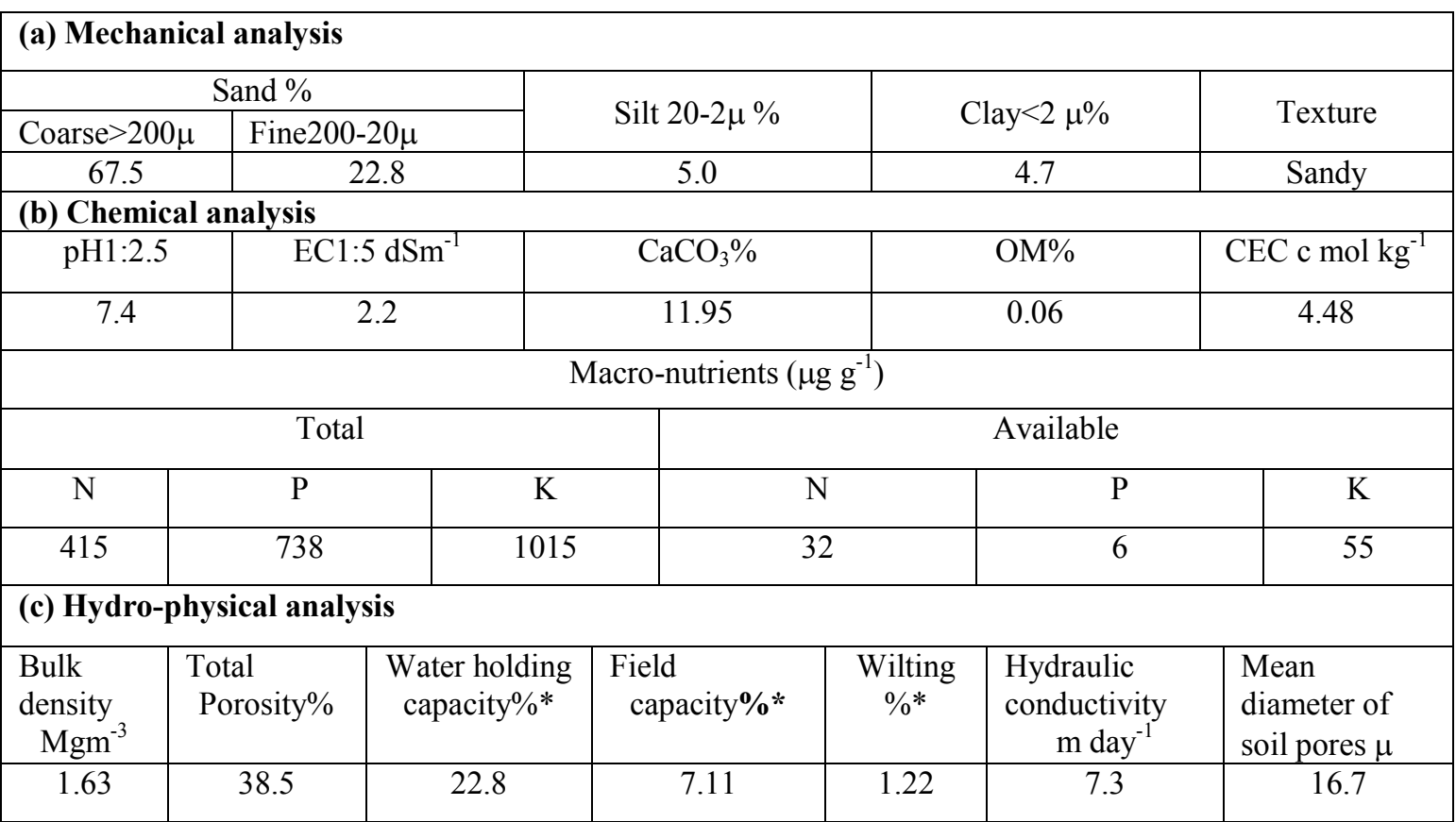

*on dry weight basis

* G1, was prepared under grafting conditions: 0.12 $\mathrm{H}_{2} \mathrm{O}_{2} / \mathrm{RS}$ ratio, $0.1 \%$ ferrous ammonium sulfate, and 2 acrylonitrile/RS ratio, for $3 \mathrm{~h}$, at $50^{\circ} \mathrm{C}$, using $\mathrm{KOH}$ as hydrolyzing agent and $\mathrm{AcOH}$ for neutralize the $\mathrm{pH}$-value to $\sim 6-7$.
* G2, was prepared under grafting conditions: 0.12 $\mathrm{H}_{2} \mathrm{O}_{2} / \mathrm{RS}$ ratio, $0.1 \%$ ferrous ammonium sulfate and 2 acrylonitrile/RS, for $3 \mathrm{~h}$, at $50^{\circ} \mathrm{C}$, using $\mathrm{KOH}$ as hydrolyzing agent and $\mathrm{HNO}_{3}$ for neutralize the $\mathrm{pH}$-value to $\sim 6-7$. 
* G3, was prepared under grafting conditions: 1.8 $\%$ persulfate, $0.9 \%$ isulfate, and 2 acrylonitrile/ $\mathrm{RS}$ ratio, for $3 \mathrm{~h}$, at $45^{\circ} \mathrm{C}$, using $\mathrm{KOH}$ as hydrolyzing agent and $\mathrm{HNO}_{3}$ for neutralize the $\mathrm{pH}$-value to $\sim 6-7$.

* G4, was prepared by grafting the partially cyanoethylated RS, under the same conditions of hydrogel \# 3, using $\mathrm{AcOH}$ for neutralize the $\mathrm{pH}$ value to $\sim 6-7$.

2.1.3. Examined micro-organisms and media preparation. The most beneficent micro- organisms in the plants rhizosphere their abundance in the conditioned soil with higher counts indicates. The improvement of the biological activity of the soils was chosen for this study. These micro-organisms are: (i) five sps.of Rhizobia liguminosorum i.e alfa-alfa; clover; broad bean, peanuts (T110) and phasoleai, (ii) Azotobacter chroococcum, (iii) Azospirillum lipoferum, (iv) Bacillus suptlis, (v) Phosphate dissolving bacteria (Bacillus megatherium), (vi) Actinomycetes, (represented by Streptomyces aureofaciens), and (vii) Fungi. (Aspergillus niger).

Different media for microbial determinations were prepared, e.g., Nutrient agar media for total count, Modified ash medium for Azotobacter, Semi-solid malate medium for Azospirillum, Burnt Rovira medium modified by Abdel-Hafez for phosphate dissolving bacteria, Yeast extract- Malt extract agar for Actinomycetes and Martin medium for fungi $[14,15]$

After sterilization, $5 \mathrm{ml}$ of $10 \% \mathrm{~K}_{2} \mathrm{HPO}_{4}$ and $10 \mathrm{ml}$ of $10 \% \mathrm{CaCl}_{2}$ sterilized solutions were added to each $100 \mathrm{ml}$ sterilized medium and sterilized solution of $2 \mathrm{~N}$ $\mathrm{NaOH}$ was used to adjust the medium $\mathrm{pH}$ at 7.2 just before pouring.

2.1.4 Indicator plant. Wheat (triticum aestivum 1 c.v hybrid sahcka 94) was chosen in this study as the indicator plant.

\subsection{Methods}

2.2.1. Effect of RS-based hydrogels as growth promoters (the stimulative effect for the most beneficent micro- organisms in plants media (rhizosphere). This test was carried out according to the following steps: 1) In $100 \mathrm{ml}$ flasks, each medium was inoculated with the proper micro -organism and incubated at $28-30^{\circ} \mathrm{C}$ for 7 days for total microbial count and 15 days for the other micro -organisms. 2) After incubation period, $5 \mathrm{ml}$ from each inoculated medium were diluted to $400 \mathrm{ml}$ using the same medium (but not inoculated with the micro -organism) and was poured into sterile Petri dishes $(10 \mathrm{ml} /$ each dish), that contain $100 \mathrm{mg}$ of the examined hydrogels and incubated for 15 days at a degree of $28-30^{\circ} \mathrm{C}$. The same experiments were triplicated. Number of colonies in each dish was counted and the mean of replicates was recorded [16].

\subsubsection{Effect of RS-based hydrogels on beneficent} microorganisms. A completely randomized greenhouse experiment with three replications for each treatment was conducted as follows: 1) Three $\mathrm{kg}$ capacity plastic pots $(15,13$ and $13 \mathrm{~cm}$ in the upper diameter, lower diameter and height, respectively) were used. 2) Six hundred grams of untreated soil were packed in the bottom of each pot to simulate a bulk density of $1.63 \mathrm{~g} \mathrm{Mg} . \mathrm{m}^{-3}$.then two $\mathrm{kg}$ of treated soil with the hydrogels at the rates of 2.5 and $5 \mathrm{~g} / \mathrm{kg}$ soil (on dry weight basis), were packed over the previous layer with the same bulk density. After that, $150 \mathrm{~g}$ of untreated soil was also packed in the pots as a surface layer. Water was slowly added to allow complete hydration of the conditioners. After two days, each pot was planted with the seeds of the indicator plant, which were previously soaked overnight in water.

Irrigation was carried out once a week. Amounts of water needed to reach $60 \%$ of the total water holding capacity of each soil were applied.

A complex fertilizer (Nutrien) $0.5 \mathrm{~g} / \mathrm{l}$ was used as a fertilizer solution. Its components were as follows:

Macro nutrients: N $27 \%$, P $11 \%$ K $22 \%$ and Mg $0.12 \%$; Micro nutrients: $\mathrm{Zn} 0.27 \%$, Fe $0.17 \%$, Mn $0.15 \% \mathrm{Cu} 0.31 \%$, and Mo $0.003 \%$.

After 60 days from sowing, plants were evaluated and some biological properties of the soil were determined. These include: 1) Microbial counts.; i.e., total bacterial count, Azotobacter sp., Azospirellum, phosphate dissolving bacteria, total count of fungi and actinomycetes, using the proper medium for each microorganism [16]. 2) Enzymes activity. i.e., activity of dehydrgenase [16] and activity of phosphatase [17].

\section{Results and Discussion}

3.1 Effect of RS- based hydrogels as growth promoters (the simulative activity) for the most beneficent micro-organisms in plants media (rhizosphere). Data presented in Figure 1 shows the effect of the prepared hydrogels, applied in $2.5 \& 5 \mathrm{~g} / \mathrm{kg}$ soil, on the count of the most beneficent microorganisms, in comparison to the control treatment (without hydrogel), where number of recorded colonies were $<40 /$ dish. The observed data are in agreement with the knowledge that, there's a direct relation between the colonies and the simulative effect, whereas, the prepared hydrogels have stimulating behavior for the most of examined microorganisms.

In this respect, G 2 and G4 indicate their growth promoting action (stimulating activity) for most of the examined microorganisms. The effect of the other two formulations, i.e., G1 and G3 was somewhat lower 
than that of G2 and G4 particularly with Rizobia, Azotobacter and actinomycetes. This is probably related to the effect of both nitrogen content as well as type of acid used to neutralize the hydrogels produced. Whereas, the nitrogen contents in the case of $\mathrm{G} 1, \mathrm{G} 2$,
G3 and G4 were 8.04, 8.04, 7.11 and 8.91\%, respectively. In other words, due to the higher ionization of $\mathrm{HNO}_{3}$ than $\mathrm{AcOH}$, the hydrogel $\mathrm{G} 2$ is higher efficiency than G1.

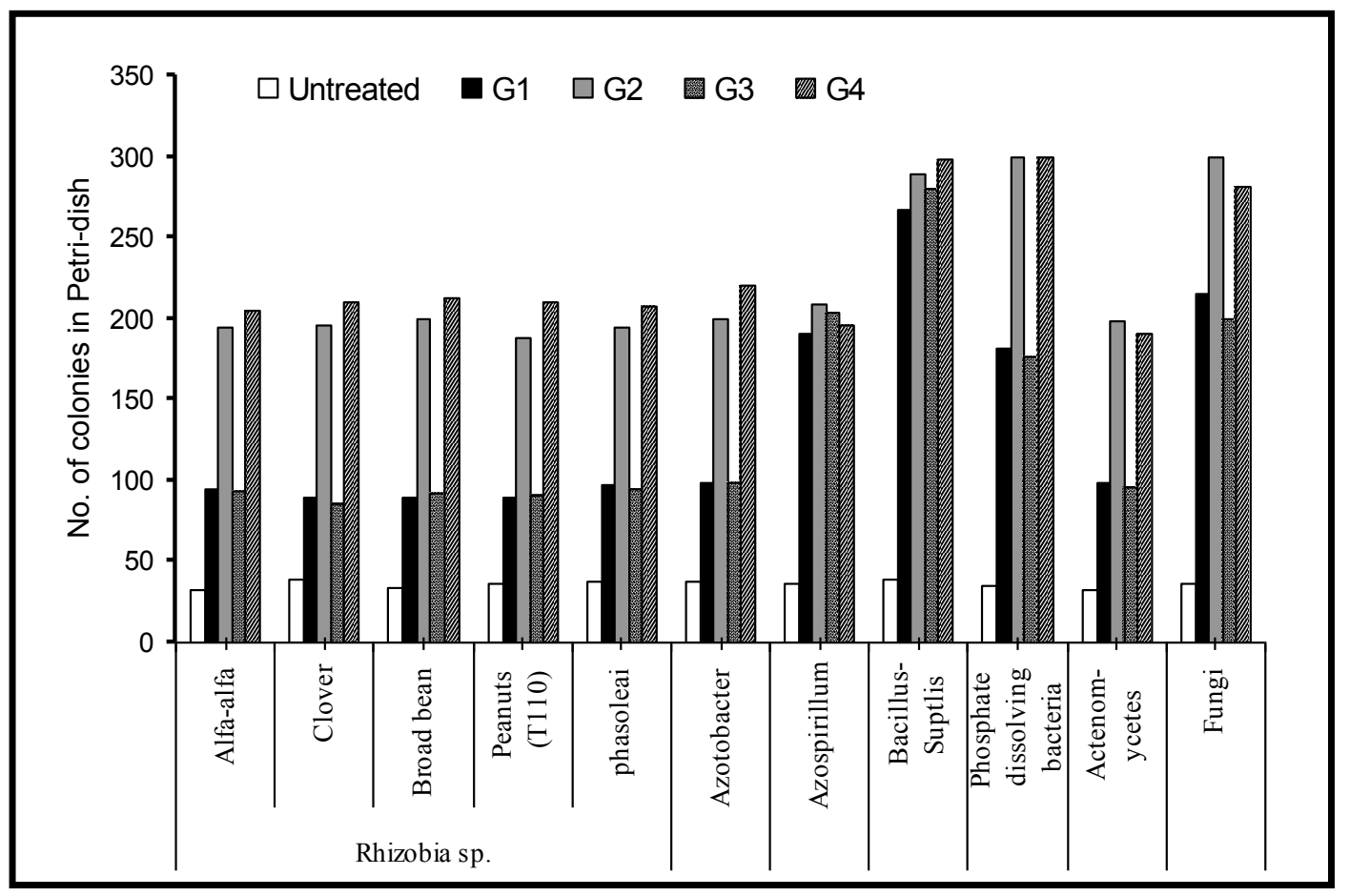

Figure 1: Effect of the prepared hydrogels as growth promoters for the most beneficent micro organisms in plants rhizosphere.

3.2. Effect of RS-based hydrogels on count of some micro-organisms in rizosphere of wheat grown in sandy calcareous soil. (cfu $\mathbf{g}^{-1}$ soil). Increasing the low numbers of microorganisms (bacteria, fungi, actinomycetes) in sandy and sandy calcareous soils could be considered as one of the indicators of improving their simulative activity. Data presented in Figure 2 refer to such improvement due to soil conditioning with the examined hydrogels.

Examining the effect of applying the low rate of the hydrogel (G1) under study to the sandy calcareous soil (i.e., $2.5 \mathrm{~g} / \mathrm{kg}$ soil) and after 60 days of plantation, number of total bacteria count, Azotobacter, Azospirellum, phosphate dissolving bacteria, total fungi and actinomycetes were increased by 70.0, 33.3, 25.0, 50.0, 77.8 and $87.5 \%$, respectively. Relevant values were $240,77.8,125,160,122.2$ and $200 \%$ for $\mathrm{G} 2 ; 90,66.7,75,120,55.6$ and $137.5 \%$, for G3 and $168,100,137.5,180,100$ and $212.5 \%$ for $\mathrm{G} 4$.

By doubling the application rate of examined hydrogels to be $5 \mathrm{~g} / \mathrm{kg}$ soil, number of microorganisms mentioned above were decreased but in all cases were still higher than the control treatment (non conditioned soil with hydrogels). In this respect, increments in number of microorganisms over that of the control treatment were $10.0,160,50$ and $140 \%$ for total bacteria; 22.2, 44.4, 44.4 and $55.6 \%$ for Azotobacter; 12.5, 112.5, 50 and $87.5 \%$ for Azospirellum; 40, 110, 90 and $150 \%$ for phosphate dissolving bacteria; $33.3,100,33.3$ and $77.8 \%$ for total fungi and $112.5,150,112.5$ and $187.5 \%$ for Actinomycetes by applying the hydrogels G1- G4, respectively.

Since most of the biological reactions in the soil are enzymatic changes, enzymes activity could be considered as another parameter to characterize the direct effect of examined hydrogels in the soil. In this respect, both dehydrogenase and phosphotase activities were assayed. Data in Figure 3 indicate the increase in the activity of both enzymes by soil conditioning. Regarding the lower application rate of examined hydrogels, i.e., $2.5 \mathrm{~g} / \mathrm{kg}$ soil, the biological activity of soil enzymes raised by 576, 637, 542 and $709 \%$ for dehydrogenase, and by $25,77,40$ and $97 \%$ for phosphotase, in the case of applying G1, G2, G3 and $\mathrm{G} 4$, respectively. While, in the case of applying higher rate of hydrogels $(5 \mathrm{~g} / \mathrm{kg}$ soil), such increments in the enzymes activity in wheat rizosphere is over that of the control treatment (non-conditioned soil), were somewhat decreased to be 522, 644, 607 and $667 \%$ for dehydrogenase and 5, 65, 33 and $80 \%$ for phosphotase, in the same sequence of gels (G1-G4). 


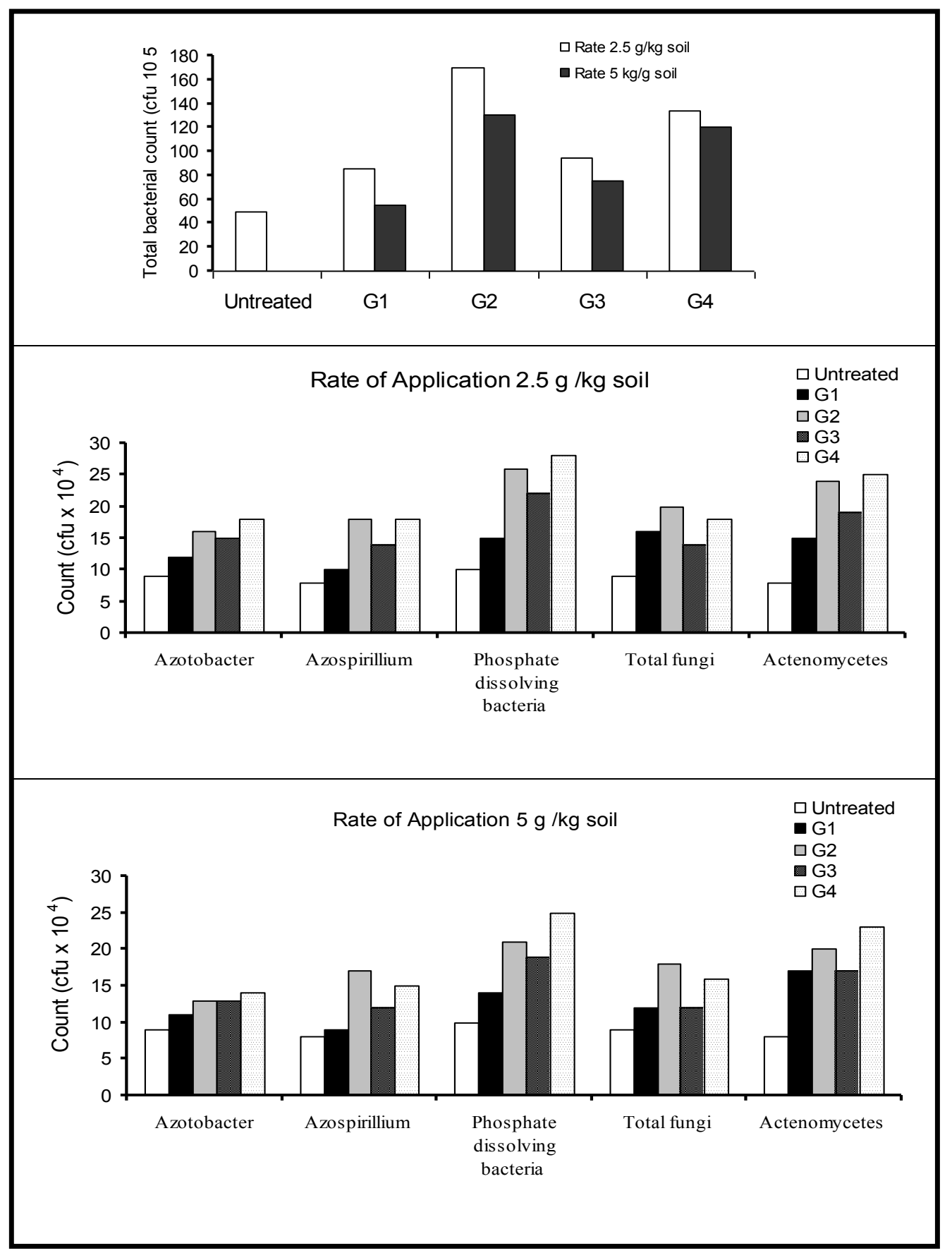

Figure 2. Effect of examined hydrogels on count of some micro-organisms in wheat rhizosphere.

These foregoing results are expected. Whereas, the higher moisture retention in the conditioned soil is due to applying higher rates of hydrogels, and their adverse effects on the aeration of the root zone, as a result of increasing soil microporosity (water holding pores), on the expense of its macroones (drainage pores responsible for aeration of the rhizosphere) [18, 19], may be the reason for such negative effect by applying the higher dose of examined hydrogels. Previous studies came to similar conclusion [20-22]. This indicates that the efficiency of applying the lower rate of hydrogels is better for soil conditioning without adverse effects on plant growth and the beneficial microorganisms of the soil.

\section{Summary}

Four rice straw (RS)-based hydrogels were prepared to be utilized as conditioners for desert soil. These behavior were related to beside their contribution effect in improving the hydro-physical properties of soil, their ability to absorb a lot of water in soil (7610, 3318, 3008 and 7061 in distilled water; while $6107,2025,3128$ and $3789 \%$ in Nile water ( $\sim 250 \mu \mathrm{g}$ g-1 salts) for Gel 1, Gel 2, Gel 3 and Gel 


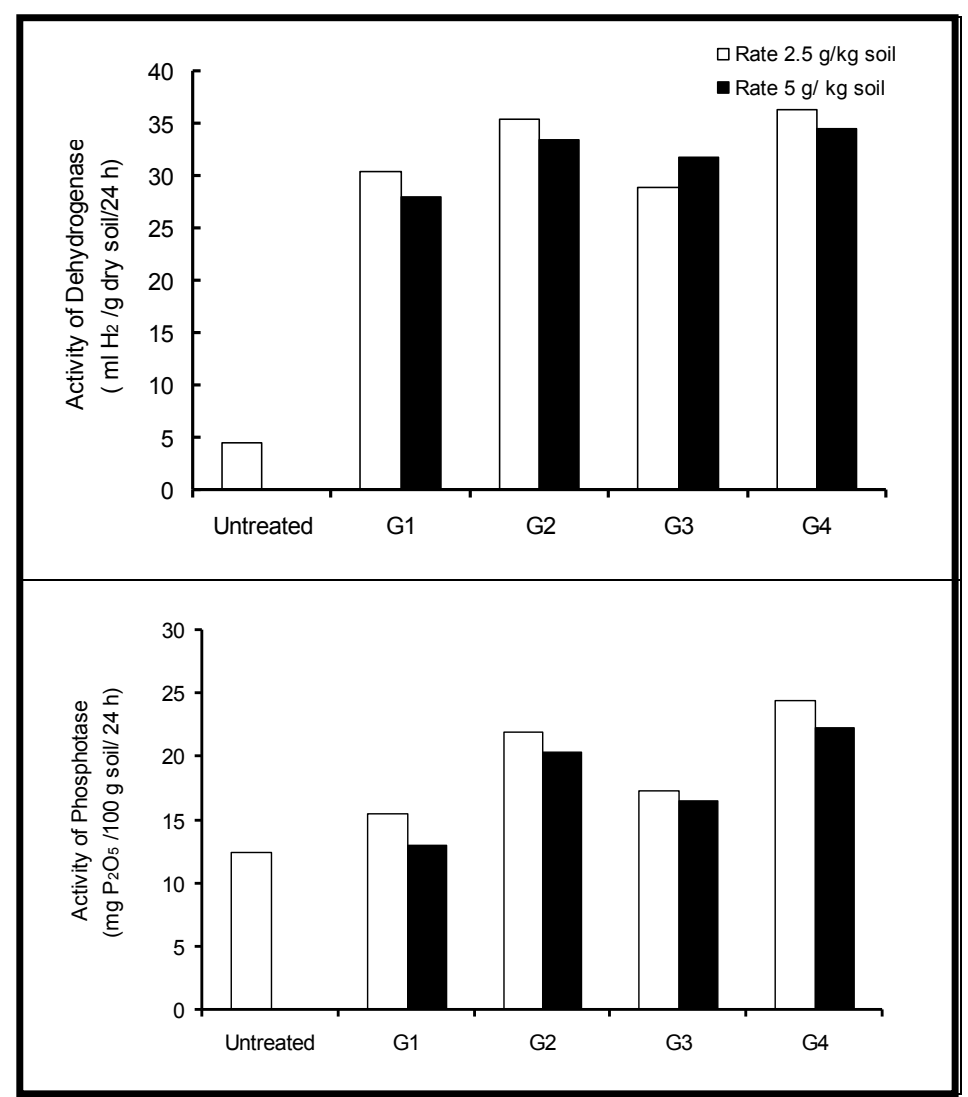

Figure 3: Effect of examined hydrogels on activity of dehydrogenase and phosphates in wheat risosphere.

4 , respectively). Therefore, they minimized the loss of water through irrigation. In this work, their effects on the counts of some soil microorganisms strains [five sps. of Rizobia liguminsorum, Azotobacter chroococcum, Azospirillum Lipoferium), Bacillus supllis, phosphate dissolving bacteria (Bacellus megatherium), Actinomycetes (Crepresented by streptomyces aureofaciens.) as well as fungi (Aspergillu niger)], and the activity of both hydrogenase and phosphotase were evaluated. The results indicated that the stimulating effect of studied hydrogels, with respect to total bacterial count, were in the order $\mathrm{G} 2 \geq \mathrm{G} 4>\mathrm{G} 3 \cong \mathrm{G} 1$. This order is probable related to the higher nitrogen contents of the produced hydrogels, as results of using hydrogen peroxide-ferrous ammonium sulfate in grafting initiated system than that produced from using persulfate-bisulfite initiation system, as well as using nitric acid to neutralize the final hydrogels instead of acetic acid. Two rates of the investigated hydrogels; namely 0.25 and $0.5 \%$ were applied. The lower application rate $(0.25 \%)$ was preferable than the higher ones $(0.5 \%)$, due to the adverse effects of applying higher rate on the aeration of the root zone.

\section{Acknowledgment}

This research work was carried out under grant from Science and Technology Development Fund (STDF), sponsored by the Egyptian Ministry of High Education and Scientific Research, with Project ID: 370

\section{References}

1. Tayel, M.Y.; O.A. El-Hady, Acta Hortic. 1981, 119: 247-256.

2. El-Hady, O.A.;Tayel, M.Y.; Lotfy A.A. Acta Hortic 1981,119: 257-266.

3. Pieh, S.M.; El-Hady, O.A. Egypt, J. Soil Sci. 1990, 30 (1-2)159-167.

4. El-Hady, O.A; Abd El-Hady, b.m.; Rizk, N.A; El-Saify, E.S. Egypt J. Soil Sci 2003, 43: 215229.

5. Nus, J.L.; Smith, R.J.1992. Effect of rate, bulk density and salinity on expansion and water holding capacities of cross- linked polyacrylamide and starch - amended soil and sand. Agron. Abstr. 1992, 181-192.

6. Boatright, J.L.;Zajicek, J.M.; Mackay, W.A..Hort. Science 1995, 30 (4), 896-906. 
7. El-Saied, H.; Ahmed, I. Waley; Altaf, H. Basta, Plast. Polym. Technol. Eng 2000., 39: (5) $905-$ 926. http://dx.doi.org/10.1081/PPT-100101412

8. El-Saied, H.; Basta, A.H.; El-Hady, O.; Waley, A.I. Plast. Polym. Technol. Eng. 2004, 46 (3), 311-319. http://dx.doi.org/10.1080/03602550601155831

9. El-Saied, H.; Waley, A. I., Basta, A.H. El-Hady, O.A. and Camilia El-Dewiny Enhancing the utilization of rice straw as potential low cost hydrogels.Pt.I: Role of grafting approach on characterization of hydrogels produced. Submitted for Publication (2011).

10. Brady, N.E.. The Nature and Properties of Soils, 11th Ed. Mac Millan Publication New York, USA 1990.

11. Abo-sedera, S.A.. J. Agric. Sci. Egypt 2006, 14 (2): 613-623

12. Page, A. L; Miller, R.H.; Keeney D.R. Methods of soil analysis part 2, 2nd ed. Am. Soc. Agron. Inc.;Soil Sci Soc. Am. In. Madison, Wisconsin USA 1982.

13. Klute, A. Methods of soil analysis part 1, 2nd ed. Am. Soc. Agron. Inc.; Soil Sci Soc. Am. In. Madison, Wisconsin USA 1986.

14. Atlas, R.M. Handbook of microbiological media. CRC press, second edition, New York. ISBN: 0-8493-1818-1, 2005.
15. Abdel-Hafez, A.M. Some studies on acid producing micro-organisms in soil and rhizosphere with special reference to phosphate dissolvers. Ph.D. Thesis, Faculty of Agriculture, Ain Shams University, 1966.159 pp.

16. Skujins, J.. Dehydrogenase: An indicator of biological activities in arid soils. Soil Bull. Ecol. Res. Comn. 1973, 17: 235-241.

17.Katai, J.B.; Bekecs, S.. Debrecini Agrogrudmgnyi Egyetem Tudomgnyos Kzlemenyi 1986, 26: 137-15.

18. El-Hady, O.A.; Wanas, Sh.A. J. Appl. Sci., Res 2006, 2 (12), 1293-1297.

19. El-Hady, O.A.; Abo-Sedera, S.A. International J. of Agric. and Biology 2006, 103 (6) 376-384.

20. El-Hady, O.A.; El-Dewainy, C. J. Appl. Sci. Res.2006, 2 (11), 890-898.

21. El-Hady , O.A. , Abd El-Kader, A.A..; Abou Sedera, S.A. Hydrophilic polymers for improving the conditioning effect of manures and organic composts. III. Bio-chemical properties of sandy soil planted with tomato. 7th Nat. Conf. Egypt Soil Science Society (ESSS), Dec. 27-28, 2004, Cairo, Egypt. Paper No. P.3.14. 2004.

22.El-Hady , O.A. , Abd El-Kader, A.A.; Shafi, A.M.. Australian J. Basic and Applied Sciences 2009, 3 (4), 3145-3151. 